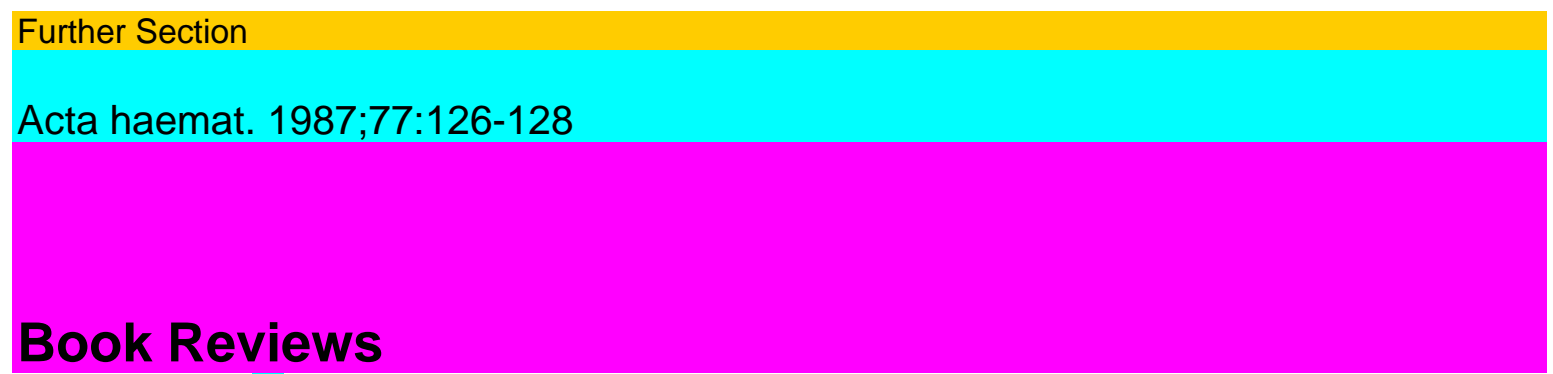

\title{
Barbara Blauhuí
}

Albumin and the Systemic Circulation

Current Studies in Hematology and Blood Transfusion, vol. 53

Karger, Basel 1986

XIV + 234 pp.; SFr. 177.-/USS 98.50

ISBN 3-8055-4367-0

Albumin, by far the most abundant blood protein, is readily recovered from pooled human plasma and presents as a well defined galenical preparation for therapeutic purpose in anaesthesiology, intensive care and plasma exchange wards. To organize a workshop on the role of albumin among other volume-substitutive colloids (gelatin, dextran, hydroxyethylstarch) in maintenance of colloid osmotic pressure was therefore a most timely task. With 14 chapters on 234 pages, 50 figures and 20 tables, this book is a mixture of original data and reviews of the literature. After having read the book, clinicians should be sufficiently updated for solving their dilemma in choosing the right volume replacement fluid for their patients. Sure enough most chapters option for choosing albumin, but questions are left open about gelatin versus dextran versus hydroxyethylstarch. I enjoyed reading the papers contributed by the editors themselves who present a lot of original data that are compared to a list of often recent references. The finding of Blauhut that albumin and furosemide work in concert to stimulate urinary excretion in fluid retention syndrome is remarkable. The chapter by Grünert (Ulm) is a teaching text which in basic terms explains Starling's equation and analyses the importance of colloid osmotic pressure measurement to dosage recommendations for albumin. The chapter by Demling (Boston) is built on the relative importance of the microvascular membrane, interstitial space and fluid transport for edema formation; the paper ends with a short appraisal of non-protein colloids in fluid resuscitation. Fogli $\alpha$ et al. (Los Angeles) present original data collected during a study on iatrogenic myocardial edema and Houpt (Detroit) writes a teaching text based on his own experience and 53 unfortunately mostly older references. Hunt et al. (San Francisco) have peformed studies on edema and anaemia on wound healing and infection. Part of the results are included in their chapter, which is rather poorly organized and difficult to read. The next two chapters by Hilton (Galveston) on albumin in postburn fluid resuscitation and by Oberman (Ann Arbor) on fresh-frozen plasma are good state-of-the art reviews, the latter with excellent references of newer date. The next two chapters compare albumin to freshfrozen plasma (Tullis, Boston) and to colloid substitutes (Lutz et al., Heidelberg). Shoemaker (Los Angeles) brings in a lot of data from his own research on oxygen transport in critically ill patients under fluid therapy with special emphasis on substituting patients suffering from acute respiratory distress syndrome. Boutros (Cleveland) briefly recollects clinical indications for albumin in intra- and postoperative therapy, and Kaufman et al. (New York) in a scholarly paper present original data on their colloid, viz cristalloid study in 26 patients with shock: their conclusion that albeit cardiac function and haemodynamic stability can be restored to 
the same physiological endpoints utilizing either albumin, hydroxyethylstarch or saline is followed by 6 other conclusion points which all give colloids a clear advantage over saline. Unlike the now frequently organized 'consensus conferences', this meeting left complete freedom of opinion to every participant and leaves the synthesis open to the reader, a task that Bergmann (Linz) tries to assume for us in his concluding synopsis at the end of the book. A very nice aspect of the book are the discussions after the respective chapters. In contrast to other workshop discussions, the ones included here are thorough, well edited and reflect a lively question-and-answer discussion that has taken place during the workshop. The reader may draw a lot of inside information from these discussions in which such clinicians as Georgieff (Heidelberg), Hunt (San Francisco), Shoemaker (Los Angeles), Suter (Geneva) and Tullis (Boston) elaborate on fluid substitution. In fact, there are as much as 36 pages set in small print devoted to these discussions in which all participants took part and expressed a lot of personal opinions.

This book contains contributions of a good selection from au thors in the USA, Germany, Austria and Switzerland, and although data of important French, British, Dutch, Scandinavian and Japa nese authors are left out, I recommend the book as an update in a field that brings anaesthesiology, surgery and transfusion medicine into close contact. U. Nydegger, Bern

Beutler Ernest

Red Cell Metabolism

Methods in Hematology Livingstone, Edinburgh 1986126 pp.; E28.00 ISBN 0-443-03310-2

This volume is a most valuable source of information for hematologists and biochemists. The chapters on the measurement of met abolic intermediates with enzymatic/fluorometric techniques, on glutathione and on glycolytic enzymes are written by Ernest Beut ler. Grant Bartlett is the author of the chapter on chromatographic techniques for metabolic intermediates. Kouichi R. Tanaka and Neil A. Lachant have contributed the chapter on radiorespirometric evaluation of the hexose monophosphate shunt. The last two chapters are dealing with density-dependent red cell separation and electrophoretic analyses of polymorphic red cell enzymes. They are written by Laurence Corash/Eloise Giblett and Jeanne E. Enderson, respectively. The recommended laboratory methods are de scribed in detail, including the preparation of the specimens and reagents, the instrumentation as well as the assay procedures. This book will certainly find its place in the libraries of all units of hema tology or biochemistry. H.R. Marti, Aarau Book Reviews 127

A. Hagenbeck, B. Löwenberg(eds)

Minimal Residual Disease in Acute Leukemia 1986

Nijhoff, The Hague 1986

XIV + 393 pp.; Dfl. 175.-/US\$ 76.50/E 48.50

ISBN 0-89838-799-X 
This book contains full reports presented at a recent conference on residual disease in leukemia. It is loosely divided into four parts. Part I, the most extensive one, deals with problems related to the classification of leukemia and the detection of residual malignant cells by different methods, including the marking of cell surfaces with specific monoclonal antibodies. Recent developments of molecular biology and cytogenetic methods are included as well. Several attempts were made to find correlations between tumor cell detection and the likelihood of relapse, for wich purpose both leu-kemic and clonogenic cells have to be recognized as such. Limitations, such as specificity, low sensitivity or poor cellular reproduction, are also considered.

Part II describes variations of chemotherapy regimens aiming at an increased rate of complete remission considering the grade of malignancy. Part III is dealing with autologous bone marrow transplantation as a tool to eradicate minimal residual disease. The main problem, elimination of residual leukemic cells in the graft, is intensively discussed. Studies are presented in which bone marrow was used either unpurged or purged by monoclonal antibodies or chemical agents. Part IV, finally, deals with allogeneic bone marrow transplantation (HLA-matched and unmatched). Minimization or avoidance of graft-versushost disease by $\mathrm{T}$ cell depletion and by optimal conditioning of patients are evaluated, considering also the relative influences of donor/recipient histocompatibility.

This book delivers a good overview over the latest advances in leukemia research, correlating relapse with residual malignant cells. It contains valuable informations for both clinicians and ba sic researchers. Although neither an ideal method to recognize re sidual malignant cells nor a perfect therapy to prevent leukemic re lapse are presented, the book offers many new ideas and strategies. The comprehensive reference lists after each article represent a val uable source of additional information. $\quad$ B. Rentsch, Bern D.Linch,A.P.Yates Haematology

Colour Aids

Livingstone, Edinburgh 1986123 pp.; E5.95 ISBN 0-443-02842-7

This booklet contains the basic knowledge of haematology and is a helpful guide for medical students and technicians. Micropho-tographs of blood and bone marrow smears are commented with brief texts covering all aspects of haematology, including common laboratory procedures and some clinical illustrations. D. Linch is a Senior Lecturer at the Middlesex Hospital Medical School, A.P. Yates is a Chief Technician at the University College London.

H.R. Marti, Aarau

E.L. Reinherz, B.F. Haynes, L.M. Nadler, I.D. Bernstein (eds)

Human T Lymphocytes

Leukocyte Typing II, vol. 1

Springer, Berlin 1986

$\mathrm{XX}+549 \mathrm{pp}$;:DM240.-

ISBN 3-540-96175-5

This book is a collection of the written results of participants attending the 2 nd International Workshop on Human Leukocyte Differentiation Antigens held in 1984. The volume is a comprehensive review of the current status in T cell typing as well as an anthology on existing antibodies (mainly monoclonal) against the major clusters of differentiation (CD) 
groups of T cell antigens. About 200 anti-T-cell monoclonal antibodies are now known for their effects on $\mathrm{T}$ cell function, and it appears that between mere binding and influence on function there is a wide variance. It is apparent that the editors have above all emphasized this functional modulation of lymphocytes by monoclonal antibodies, since 20 chapters of the book are grouped under the heading 'Functional Studies' - thus outnumbering the 3 chapters on biochemical studies, the 6 chapters on phenotypic characterization of T cell leukemias and lympho-mas, the 2 chapters on phylogeny and on histology, the 4 chapters on the study of antibodies reactive with antigens of activated T cells, 1 chapter on $T$ cell leukemia-associated antigens as well as the 5 chapters on new $\mathrm{T}$ cell markers. The book has 549 pages and is a directory guide covering the currently known antigens on $\mathrm{T}$ lymphocytes. The reader should not expect to find a coherently written text in a book that includes 43 chapters; the overlap is considerable. Nevertheless, the editors have succeeded in laying a 'red thread' that makes the book easier to use. The key word index is exhaustive and helps one to find the desired entry immediately.

U. Nydegger, Bern

S. Dawids, A. Bantjes(eds)

Blood Compatible Materials and Their Testing

Kluwer Academic Publications, Dordrecht 1986 X + 375 pp.; Dfl. 220.-/USS 106.50 ISBN 089838-813-9

This volume presents an excellent, concise survey of current European research concerned with the complex physiochemical problems arising at the interface between blood and artificial surfaces, and with the study and design of new materials minimizing blood reactions occurring in extracorporeal circulation systems, in cardiovascular prostheses, etc. The book presents the papers originally presented at the 1984 and 1985 meetings on haemocompatible materials, sponsored by the Commission of the European Communities. The meetings brought together an impressive group of particularly strong French, Italian and Dutch teams, as well as British, German and Greek scientists in the field. The 41 papers presented cover the following areas: blood reactions due to polymer interaction, physiochemical factors in blood compatibility, methods of testing for compatibility, modifications of polymer surfaces, sor-bents for blood components, and biological alteration of surfaces of synthetic materials. Highly stimulating accounts are given of the diverse activities of the groups comprising materials scientists, polymer chemists, specialists in surface physics, biologists, phys128

Book Reviews

iologists and clinicians. Questions as to protein adsorption, cell adhesion and aggregation, activation or inhibition of the clotting system, tissue reactions, etc., are brought into relation with the properties of synthetic materials and their surfaces, some altered by layers of anticoagulants, some inherently antithrombogenic, and also with flow conditions at the interface, with problems of toxicity, etc. A wide variety of in-vivo and in-vitro testing methods is presented and discussed, ranging from enzyme immunoassay, resonance thrombography, radiolabeling, ellipsometry, to scanning electron microscopy. Consensus about optimal standardization of tests that are necessary and sufficient has not been reached however. The practical utilization of the knowledge and know-how obviously lies in the areas of improved biocompatibility of hemodialyzers, blood oxygenators, plasmapheresis systems, heart valve and vessel pros-theses, and many other devices used in modern medicine, the 
laboratory, and biotechnology. Progress is made rapidly, many new approaches and technics seem highly promising, as is witnessed by this volume which provides very good overview and insight into this field of endeavor. Moreover, the book is of great assistance in leading the way into the widely dispersed literature covering in detail the many problems that need be mastered when blood is brought into contact with man-made material.

U. Gessner, St. Gallen

T.H.J. Huisman(ed.) The Hemoglobinopathies

Livingstone, Edinburgh 1986 VII+ 200 pp.; E35.00 ISBN 0-443-03309-9

In this comprehensive monograph, basic and advanced labora

tory methods for the detection and identification of hemoglobino

pathies are described and evaluated. Ethnic background, frequency

and clinical implications of abnormal hemoglobins are mentioned.

The book is divided into 9 chapters which are written by most

competent authors from the USA, Italy, Yugoslavia and New Zea

land. The world-wide frequent use of this excellent standard book

is easy to predict. H.R. Marti, Aarau

E. Piskin, A.S. Hoffman (eds) Polymeric Biomaterials

NATO ASI Series, Series E: Applied Sciences, No. 106 Kluwer Academic Publications, Dordrecht 1986 VII + 258 pp.; Dfl. 150.-/US\$ 70.00 ISBN 90-247-330-30

Modern material sciences have been opening totally new and highly successful avenues for the solution of a great variety of problems - not only in technology, but also in medicine, biomedical engineering and biotechnology. Control and targeting of in-situ delivery systems for drugs or hormones; production of hard and of soft tissue implants of high degrees of biocompatibility; collection, elimination or control of biological substances as well as new analytic technics by means of active surfaces, e.g. by immobilized enzyme systems, these are the goals, to mention a few. Additional, new applications cannot be foreseen, but many will evolve with certainty. Therefore, the book 'Polymeric Biomaterials' offers a welcome introduction and overview of the state of the art. It bears good witness of the fascinating effort of an international network of scientists of highly diverse specialities, all compelled to collaborate since the knowledge in physics, chemistry, engineering, biology and medicine need be brought together. The book comprises chapters on basic knowledge about polymeric biomaterials and very informative accounts on classification, structure, synthesis, modification and fabrication of these novel materials. Fundamental phenomena involved in the interaction of materials with each other, of the materials with the biological environment, and in the resulting responses of blood and tissue components are presented and discussed. Methods of modification of polymers, physical, chemical or biomedical, in order to improve performance and biocompatibility, are included. The sections treating some areas in depth, notably those on biodegradable polymers, on composite materials (enforced by fibres and other structures), on membranes, and on hydrogels are very good. The two chapters covering methods of in-vitro and in-vivo testing, with all its challenging aspects, also are comprehensive and excellent. All 16 chapters are authoritative, well documented, and stimulating, as would be expected from any NATO Advanced Study Institute meeting which the book is the result of. The book sells at a high price - as do, curiously, all reports on NATO conferences - but it is worth it. U. Gessner, St. Gallen 